\title{
Wilson's Disease with Superimposed Autoimmune Features: A Case Report
}

\author{
Md. Wahiduzzaman Mazumder, ${ }^{1}$ ASM Bazlul Karim, ${ }^{2}$ Nazma Begum, ${ }^{3}$ Md. Nurullah, ${ }^{4}$ Lina Florance Karmoker ${ }^{5}$
}

\begin{abstract}
The association of Wilson's disease (WD) with autoimmune hepatitis (AIH) has rarely been documented. The difficulties in differential diagnosis of WD and AIH have seen specially in the paediatric population. Children with WD specially in younger ones, may have clinical features indistinguishable from autoimmune hepatitis. We report a case of 8 -year old girl child who presented with jaundice, anaemia, leg oedema and arthritis. Ultimately the patient was diagnosed as a case of WD with AIH after meticulous investigation. Treatment was started with prednisolone, d-penicillamine and subsequently prednisolone was tapered with addition of azathioprine. D-penicillamine was stopped, with clinical and biochemical improvement and zinc was added to continue life-long. Follow up after 8 months of initial treatment she was non anaemic and non-icteric. Her leg oedema and arthritis also subsided. Liver biochemistry returned to normal level. It is important therefore to recommend strongly a thorough screening for AIH in patients with initial diagnosis of WD and also screening for WD for patients presenting with $\mathrm{AIH}$. So a combined therapy may be of early benefit.
\end{abstract}

Key words: Autoimmune hepatitis, Wilson's disease, Prednisolone, Penicillamine.

\section{INTRODUCTION}

Wilson's disease (WD) is an autosomal recessive disorder of copper metabolism with a prevalence of approximately 1:3000. Mutations of the copper transforming ATPase, ATP7B can lead to decreased billiary copper excretion and accumulation of copper predominantly in the liver and extra hepatic organs such as brain and the cornea. ${ }^{1}$ The disease typically begins with an asymptomatic period of subclinical hepatitis and progress to liver cirrhosis and neuropsychiatric symptoms. A small proportion of patient may present with acute liver failure (ALF), without pre-existing clinical signs of liver diseases. ${ }^{2,3}$ Autoimmune hepatitis (AIH) is a chronic necro-inflammatory liver diseases characterized histologically by a dense mononuclear cell infiltrate in the portal tract and serologically the presence of non-organ and liver specific auto antibodies and increased level of Immunoglobulin $\mathrm{G}$ ( IgG) in the absence of known etiology. ${ }^{4,5}$ Autoimmune hepatitis may be overlapped by other liver diseases with proven or possible autoimmune background, such as primary billiary cirrhosis or primary sclerosing cholangitis. ${ }^{6,7}$

Co-existence of WD with AIH may present sometime with a diagnostic problem. Patients with WD may show features of AIH. In this paper we present a patient with evidence of WD along with several generally accepted features of autoimmune hepatitis, i.e., co-existence of WD and AIH. Though WD in children is not an

\section{Authors' information:}

${ }^{1}$ Dr. Md. Wahiduzzaman Mazumder, Assistant Professor (Paediatric Gastroenterology), Bangabandhu Sheikh Mujib Medical University, Dhaka.

${ }^{2}$ Dr. ASM Bazlul Karim, Professor and Chairman (Paediatric Gastroenterology), Bangabandhu Sheikh Mujib Medical University, Dhaka.

${ }^{3}$ Dr. Nazma Begum, Associate Professor (Paediatrics), Manikganj Medical College, Manikganj.

${ }^{4}$ Dr. Md. Nurullah, Resident (Paediatric Gastroenterology), Bangabandhu Sheikh Mujib Medical University, Dhaka.

${ }^{5}$ Dr. Lina Florance Karmoker, Resident (Paediatric Gastroenterology), Bangabandhu Sheikh Mujib Medical University, Dhaka.

Correspondence: Dr. Md. Wahiduzzaman Mazumder, Cell phone: +880 1718601459, Email: mazumdermw@gmail.com 
uncommon diagnosis, yet we are not very much familiar about co-existence of WD with AIH. So this case report may give better information and permit a more focused investigation which will allow the cases to be diagnosed with greater frequency and accuracy.

\section{CASE REPORT}

A 9-year-old girl was referred to the Department of Paediatric Gastroenterology and Nutrition of Bangabandhu Sheikh Mujib Medical University (BSMMU) with history of jaundice for 5 months, leg oedema for 2 months, pain in the knees and ankles for 1 month. She came from a non-consanguineous family, her parents and other siblings were in good health. There was no history of recent use of offending drugs, blood transfusion or any surgery. Physical examination revealed that the girl was moderately icteric and pale. She had bipedal oedema but no ascites and organomegaly. $\mathrm{K}-\mathrm{F}$ ring (Kayser-Fleischer Rings) was present in both eyes (Fig 1).

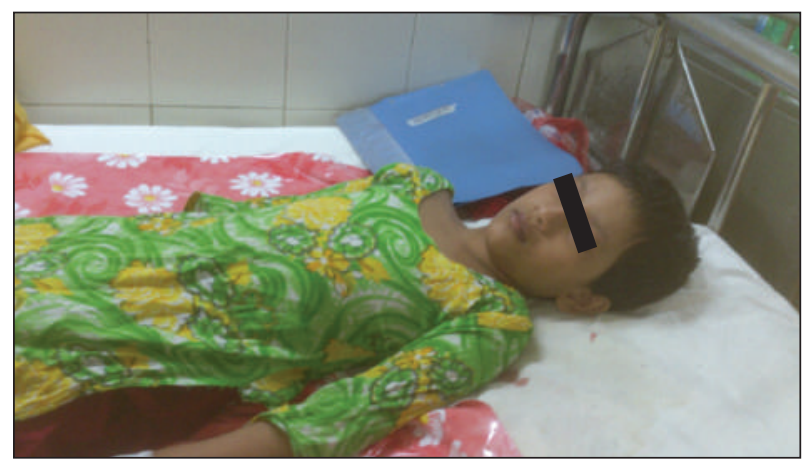

Fig. 1: The child with Wilson's disease and Autoimmune Hepatitis

Neurological examination showed no abnormalities. Laboratory investigation showed serum alanine aminotransferase (ALT) to be 86 $\mathrm{U} / \mathrm{L}$, total bilirubin $3.2 \mathrm{mg} / \mathrm{dl}$, serum albumin 2 $\mathrm{gm} / \mathrm{dl}$, increased prothrombin time. INR (International Normalized Ratio) was 2.84 (Normal-0.8-1.2). Her serum ceruloplasmin level was $20 \mathrm{mg} / \mathrm{dl}$ (Normal 20-60 mg/dl), urinary excretion of copper at baseline was $140 \mu \mathrm{g} / 24 \mathrm{hrs}$ (Normal $<100 \mu \mathrm{g} / 24$ hours), which after penicillamine challenge was $1250 \mu \mathrm{g} / 24$ hours ( $>1200$ suggestive of Wilson Disease). Viral markers for hepatitis B \& C (HBV, HCV) were negative. Serum IgG was $19 \mathrm{~g} / \mathrm{L}$ (Normal 6-16 $\mathrm{g} / \mathrm{L})$, antinuclear antibody was positive 1:400 ( $1: 40$ dilution cut-off for positive), anti-smooth muscle antibody (SMA) was negative, anti-liver kidney microsomal enzyme-1 (LKM-1) was positive, low level of complement-3 (C3) $0.5 \mathrm{~g} / \mathrm{L}$ (Normal-0.75-1.75 g/L) and complement-4 (C4) $0.14 \mathrm{~g} / \mathrm{l}$ (Normal-0.14-0.54 g/L). Liver biopsy was not done due to patient's unwillingness. The patient was treated with prednisolone and d-penicillamine initially. Subsequently prednisolone was given in a tapered-dose with addition of azathioprine. D-penicillamine stopped with clinical and biochemical improvement and zinc was advised to continue lifelong. In the last follow up after 8 months of initial treatment she was not anaemic and jaundiced with oedema and arthritis subsided. All the biochemical parameters returned to normal limit ( $\mathrm{Hb}, 11.50 \mathrm{gm} / \mathrm{dl}$, ALT-29 U/I, INR- 1.26, urinary copper $285 \mu \mathrm{g} / 24 \mathrm{hrs}$, IgG $8.8 \mathrm{~g} / \mathrm{l}$ ).

\section{DISCUSSION}

The diagnosis of Wilson's disease may be a clinical challenge. Normal ceruloplasmin levels in patients with all types of presentation of WD and the absence of Kayser-Fleischer rings are findings which lead to a missed diagnosis of WD. Nevertheless, the simultaneous presence of three characteristic features of WD: low serum ceruloplasmin, increased 24 h urinary copper, and specifically the grossly increased hepatic copper permit a diagnosis of WD without doubt. The association of Wilson's disease with autoimmune hepatitis has rarely been documented.8,9 The difficulties in differential diagnosis of WD and AIH have seen specially in the pediatric population. ${ }^{10,11}$ Patients with WD specially in younger ones may have clinical features and histologic findings on liver biopsy indistinguishable from autoimmune hepatitis. ${ }^{12,13,14}$ In some patients concomitant WD and autoimmune hepatitis cannot be excluded. ${ }^{15}$ The presence of low titre auto antibodies presumed to be secondary to exposure of antigen by hepatocyte necrosis may cause confusion. ${ }^{15}$ In WD certain features of autoimmunity are usually absent and plasma immunoglobulin are usually 
not raised. Wilson disease may quite commonly present as chronic active hepatitis, a histological picture also found in autoimmune, drug induced or viral hepatitis. Scott et $\mathrm{al}^{12}$ described in a study of 17 patients with WD who presented as chronic active hepatitis. In all these patients, tests for SMA (Smooth Muscle Antibody) ANA (Antinuclear Antibody) and hepatitis B surface antigen were negative. ${ }^{12}$ In another study, Schilisky et al ${ }^{13}$ described 20 patients with WD who presented with chronic active hepatitis, but in that series the presence of autoantibodies, which are crucial for diagnosis of $\mathrm{AIH}$, was not confirmed. ${ }^{13}$

In this case report we described one patient with WD with several superimposed features suggesting that the disease had an autoimmune background. An initial diagnosis of autoimmune hepatitis deserves treatment with steroid \& azathioprine. If response to steroid is poor, a thorough screening for WD is necessary. Failure to diagnose WD in such cases may lead to hepatic failure eventually and the necessity of liver transplantation.

\section{CONCLUSION}

It is important to recommend strongly a thorough screening for autoimmune hepatitis in patients with initial diagnosis of Wilson's disease and also screening for WD for patients presenting with AIH so that a combined therapy with prednisolone and D-penicillamine may be of early benefit.

\section{REFERENCES}

1. Scheinberg IH. Wilson's disease. J Rheumatol Supp/ 1981;7:90-93.

2. Gitlin JD. Wilson disease. Gastroenterology $2003 ; 25$ 1868-77.

3. Johnson PJ, McFarlane IG. Meeting report: International Autoimmune Hepatitis Group. Hepatology 1993;18: 998-1005.

4. Gitlin N. Wilson's disease:the scourge of copper. J Hepatol 1998;28:734-39.

5. Alvarez F, Berg PA, Bianchi FB, Bianchi L, Burroughs $A K$, Cancado EL et al. International Auto-immune Hepatitis Group Report: Review of criteria for diagnosis of autoimmune hepatitis. J Hepatol 1993;31:929-38.
6. Horsmans Y, Peret A, Bernard R, Rahier J, Geubel AP. Autoimmune chronic active hepatitis responsive to immunosuppressive therapy evolving into a typical primary biliary cirrhosis syndrome: a case report. J Hepatol 1994;21:194-8.

7. Lohse AW, Meyer ZumBuschenfelde KH, Franz B, Kanzler S, Gerken G, Dienes HP. Characterization of the overlap syndrome of primary biliary cirrhosis and auto-immune hepatitis: evidence for it being a hepatic form of PBC is genetically susceptible individuals. Hepatology 1999;29:1078-84.

8. Milkiewicz P, Saksena S, Hubscher SG, Elias E. Wilson's disease with superimposed autoimmune features: report of two cases and review. J Gastroenterol Hepatol 2000;15(5):570-4.

9. Yener S, Akarsu M, Karacanci C, Sengul B, Topalak O, Biberoglu K, et al. Wilson's disease with coexisting autoimmune hepatitis. J Gastroenterol Hepatol 2004;19(1):114-6.

10. Santos RG, Alissa F, Reyes J, Teot L, Ameen N. Fulminant hepatic failure: Wilson's disease or autoimmune hepatitis? Implications for transplantation. Pediatr Transplant 2005;9(1):112-6.

11. Wozniak M, Socha P. Two cases of Wilson's disease diagnosed as autoimmune hepatitis. Przegl Epidemiol 2002;56(I5):22-5.

12. Scott J, Gollan JL, Samourian S, Sherlock S. Wilson's disease, presenting as chronic active hepatitis. Gastroenterology 1978;74:645-51.

13. Schilsky ML, Scheinberg IH, Sternlieb I. Prognosis of Wilsonian chronicactive hepatitis. Gastroenterology 1991;100:762-67.

14. Milkiewicz P, Saksena S, Hubscher SG, Elias E. Wilson's disease with superimposed autoimmune features: report of two cases and review. J Gastroenterol Hepatol 2000;15:570-74.

15. Yener S, Akarsu M, Karacanci C, Sengul B, Topalak O, Biberoglu K, et al. Wilson's disease with coexisting autoimmune hepatitis. J Gastroenterol Hepatol 2004;19:114-16. 